\title{
Exploring risky practices, Opioid Substitute Therapy (OST) and disease transmission among prison inmates in India - A cross-sectional study
}

Anoshmita Adhikary

Manipal Academy of Higher Education

Shaikh Shah Hossain

Manipal Academy of Higher Education

Prakash Narayanan ( $\sim$ prakash.nvp@manipal.edu )

Manipal Academy of Higher Education

\section{Research Article}

Keywords: inmates, treatment, hepatitis, prison, health, risk, substance

Posted Date: September 27th, 2021

DOl: https://doi.org/10.21203/rs.3.rs-929295/v1

License: (1) This work is licensed under a Creative Commons Attribution 4.0 International License.

Read Full License 


\section{Abstract}

Background: Prison, a setting where high-risk persons including substance-use offenders are being convicted. They sometimes continue their risky behaviours which pose a risk to themselves, other prisoners and to the community.

A cross-sectional study was conducted in ten correctional homes (CHs) in West Bengal to identify the substance use, sexual and hygiene practices among prison inmates inside correctional homes.

Methods: In-depth interviews were conducted with 15 key informants posted inside prisons using an interview guide. Data were analysed using MS Excel 2019. Chi-Square tests were performed to ascertain the associations between variables.

Results: This study confirmed the availability and use of substances within prisons, and homosexual as well as drug-injecting practices of inmates. According to key informants, many $\mathrm{CH}$ inmates have had infections such as contact dermatitis, scabies, UTIs, STIs, tuberculosis, HIV, and hepatitis B and C. Limited preventive and curative services such as healthy diet, isolation and treatment for HIV and TB were provided to infected inmates. The treatment completion rate in inmates who availed OST at CHs was $96.53 \%$, while the re-addiction rate after released from prison was $98.07 \%$. The routine screening for STIs and hepatitis, distribution of condom and needles, and treatment for hepatitis were absent in most CHs. The $\mathrm{CHs}$ lack mechanisms to ensure continuous drug supply, regular follow-up and treatment completion after incarceration, partner notification, hepatitis treatment, and health promotions.

Conclusions: The improvements in infrastructure and uninterrupted health care delivery system can improve health outcomes of affected inmates and break the transmission to other inmates and general community.

\section{Background:}

Prison inmates reside in an atmosphere of violence, tension, and fear, which influences them to indulge in risky practices that increase the risk of transmitting bloodborne diseases like HIV, Hepatitis B (HBV), Hepatitis $C(\mathrm{HCV})$, and Tuberculosis $(\mathrm{TB})^{[1,2,3]}$. Globally, the percentage of HIV, hepatitis $C$, hepatitis $B$ among prison inmates is $3.8 \%, 15.1 \%$, and $4.85 \%$, respectively, which is higher than in the general population. ${ }^{[4]}$

Literature showed that substance use and dependence among prison inmates range from $10-60 \%$. ${ }^{[5]}$ Among all substance types, the use of injectable drugs is common among prison inmates. ${ }^{[6]}$ Also, injecting equipment is independent risk factor for transmission of HIV \& Hepatitis. ${ }^{[7]}$ A study from south India reported using different types of substances in one large prison to be in the range of $3-43 \%$. ${ }^{2]}$ Substances like opioids were the most commonly used among prison inmates, followed by cannabis and alcohol. [8] 
Studies conducted in jails of three major Indian cities (Delhi, Mumbai, Punjab) has shown that $63 \%$ of the prison inmates use illicit drugs. ${ }^{[9]}$ Recently, the studies conducted in West Bengal, India, showed a higher prevalence of HIV among prison inmates $(0.624 \%)$ compared to the general population $(0.23 \%)$. ${ }^{[10]}$ Another study reported unprotected sex $(81 \%)$ among prison inmates, which substantially increases inmates' risk of acquiring and transmitting HIV \& HBV. ${ }^{[11]}$ Another study in Tihar jail in Delhi estimated HBV prevalence among its inmates as $2.72 \%$, which is very high compared to general population. ${ }^{[12]}$

The published evidence on risky practices of inmates like substance use, sexual and hygiene practices and disease transmission is scarce in India. This study explores substance use, sexual and hygiene practices, and disease prevalence among inmates and the status of health interventions in the correctional homes in India through institutional data analysis and key informant interviews.

\section{Methods:}

This mixed-methodology study was conducted inside correctional homes (CHs) in West Bengal, India, from January to June 2020. A total of 10 correctional homes - seven central and three district $\mathrm{CHs}$ has permitted data collection for the study. The CHs were: Dum Dum, Presidency, Baruipore, Alipore, Balurghat, Berhampore, Midnapore, Bankura, Burdwan and Howrah. All consented medical personnel (Medical officer, Nurse, Pharmacist, etc.) posted in the correctional homes were included for the in-depth interview.

For this study, the data on prison inmates (convicts and undertrials, males and females), persons undergoing and completed opioid substitution therapy (OST), number of inmates suffering from Reproductive tract infections (STIS), HIV, Hepatitis B and C, and co-morbid conditions were collated from the $\mathrm{CHs}$. The key informants gave relevant information regarding the measures and support systems provided to inmates from their experience of working in $\mathrm{CHs}$.

A questionnaire with domains covering (Demographic Variables (Participant), Substance use, Sexual and hygiene practices and Opioid substitute therapy, Needle syringe distribution among prison inmates, and disease transmission and management process for prison inmates) was developed, validated and used for data collection in this study.

The Superintendent of Police in each $\mathrm{CH}$ were briefed about the study, centrally permission was taken and health personnel were included for the study. Face-to-face in-depth interviews with health personnel were carried out from January to March 2020. At the beginning of each interview, the purpose of the study was explained using the Participant Information Sheet. Informed consent was obtained from the respondents before participation in the study and they were assured of individual confidentiality. The participant was then asked questions. All data collected and responses obtained were kept confidential.

\section{Ethical Consideration:}


The proposal was approved by the Institutional Ethics Committee of the Manipal Academy of Higher Education (MAHE) [IEC-880/2019, Date of Approval-13/11/2019] sand Clinical Trial Registry of India (CTRI/2020/01/022802, Date of approved registration: 16/01/2020) was kept posted of the study, its progress and completion. Permission was obtained from the Director General (DG) \& Inspector General (IG) of Correctional Services, West Bengal.

\section{Data analysis:}

Quantitative analysis was done using MS Excel 2019 and represented in percentages. Chi-Square tests were carried to ascertain the association between categorical variables. A p-value $<0.05$ was considered as statistically significant. Qualitative data were represented with description. Classification of habits and

addiction-related disorders was developed in reference to existing published literature, ${ }^{[13]}$ differentiating behavioural addiction and substance-use addiction.

The percentages of different substances use, hygiene related disorders were calculated based on the approximate numbers given by the participants.

\section{Results:}

Table 1 and Table 2 described the details of participants and $\mathrm{CHs}$ visited.

\section{Prevalence of substance use among inmates in Central (CCH) and District Correctional Homes (DCH) details:}

Based on the substances used by the inmates, they were categorised into two groups - habit disorder (Bidi, Guthka, khaini, Zarda, Sadapata, paan) and addiction disorder (Cigarettes, Chullu, Opium, Heroin, beer, wine, sleeping pills, gabapentin, codeine, nitrazepam).

The proportion of inmates smoking cigarettes in $\mathrm{DCH}$ is $89 \%$, that is higher compared to $\mathrm{CCH}(82 \%)$. Chullu, a local alcoholic beverage was consumed by inmates in both central and district correctional homes as reported. Opium use among prison inmates in $\mathrm{CCH}$ was reported to be $0.7 \%$. (Figure 1) Heroin is in use in $\mathrm{DCH}(0.24 \%)$. (Figure 2) Use of substances like beer, wine, sleeping pills, gabapentin, codeine, and nitrazepam was reportedly in CHs. (Figure $1 \& 2$ ) There is a significant difference between central and district correctional homes for addiction disorders among prison inmates as the P-value is exponential (0.001).

Tobacco smoking in the form of bidi was highly prevalent among inmates in $\mathrm{CCH}$ (61.9\%) (Figure 3) than in DCH (38.75\%). (Figure 4) Other narcotic substanceslike guthka, khaini, zarda, sadapata, paan etc. were used by inmates. There is a significant difference between $\mathrm{CCH} \& \mathrm{DCH}$ for habit disorder among inmates ( $\mathrm{P}$ value -0.001 ) and $\mathrm{DCH}$ has shown higher in habit disorders compared to $\mathrm{CCH}$.

\section{Opioid substitution therapy among inmates}


All CHs provide Opioid Substitution Therapy to inmates to tackle their substance addiction and dependency disorders. For the OST management in inmates, all CHs follow National guidelines and reported providing medical diet to the inmates, methadone therapy and electroconvulsive therapy when required.

Among the inmates, $7.66 \%$ of males and $0.50 \%$ of females were availing OST. The OST services were mainly used by alcohol addicts (5.83\%) compared to heroin-addicted inmates $(1.83 \%)$.

The reported treatment completion rate among those initiated OST inside CHs was $96.53 \%$, and the readdiction rate after being released from prison was reported as $98.1 \%$.

\section{Sexual practices of inmates in $\mathrm{CHs}$}

In $\mathrm{CCHs}, 0.35 \%$ of inmates were reportedly active in homosexual practices and $0.06 \%$ were identified as sexaholics. The DCHs reported homosexual activities of $0.01 \%$ of inmates in the past three months. In male prison inmates, $0.39 \%$ were gays and $0.007 \%$ were sexaholics, as reported.

All the 15 key informants have mentioned that sexual practices were under-reported by inmates as many of the victims are either newcomers or from neighbouring Bangladesh who fear isolation and stigma on reporting such sexual exploitation to authorities.

The respondents from nine out of ten $\mathrm{CHs}$ mentioned one or more than one partners of those same-sex inmates.

All 15 participants from $\mathrm{CH}$ reported that homosexual inmates did not practise safe sex as the correctional service authority has stopped condom provision to inmates, and an isolation model is being used to prevent such sexual activities.

\section{Prevalence of STIs among prison inmates, presence of screening and management by CHs}

Among male inmates, $1.23 \%$ had herpes simplex, $0.45 \%$ had gonorrhoea, and $0.47 \%$ had genital ulcer diseases in the past three months, whereas $0.16 \%$ of female inmates had herpes simplex infection.

There might be an underestimation of the STI prevalence among inmates, as STI screening (Clinical diagnosis) has been conducted only in 4 out of 9 male $\mathrm{CHs}$, and 2 out of 7 female $\mathrm{CHs}$. All $10 \mathrm{CHs}$ provided medicines to STI infected inmates, $9 \mathrm{CHs}$ supplied bathing soaps to maintain body cleanliness, and $8 \mathrm{CH}$ s provided health education to STI infected inmates.

\section{Prevalence of hygiene-related diseases by $\mathrm{CHs}$ and gender}

The information collected from $\mathrm{CCH}$ s has shown that the inmates were suffered from hygiene-related infections such as contact dermatitis (41.79\%), scabies (7.25\%), and urinary tract infections (3.86\%) in the past three months. Among the inmates in DCHs, $7.69 \%$ had contact dermatitis, $1.96 \%$ scabies, and $1.44 \%$ had UTIs in the last three months. 
Personal Hygiene related infections like contact dermatitis (46.30\%), scabies (7.90\%), and UTI (3.47\%) among male inmates and $9.75 \%, 4.91 \%$ and $12.12 \%$ among female inmates were reported in the last three months, respectively. This shows a higher prevalence of UTIs among female inmates.

Five out of 10 correctional homes provided clean and adequate water to inmates, and only one $\mathrm{CH}$ had provided adequate space and separate blankets to the inmates. All the 15 key informants cited inadequate infrastructure facilities available to inmates, low budget allocation, and overcrowding in correctional homes.

\section{Prevalence, treatment, and management of HIV among prison inmates in $\mathrm{CHs}$}

HIV prevalence among male and female inmates was $0.51 \%$ and $1.01 \%$, respectively. Among PLHIV inmates, $80 \%$ were already availing ART, and the remaining $20 \%$ had to be linked to ART to initiate treatment. Out of 10 , only $4 \mathrm{CHs}$ reported uninterrupted provision of ART for prison inmates. All $10 \mathrm{CHs}$ gave medical diets to inmates under any medical condition. Three $\mathrm{CH}$ s were providing separate cells for PLHIV inmates out of $10 \mathrm{CHs}$. The existing systems in $\mathrm{CHs}$ were found to be inadequate for partner notification and to ensure treatment adherence of PLHIV inmates after release.

\section{Hepatitis B screening, prevalence and management by $\mathrm{CHs}$}

Nine $\mathrm{CHs}$ have reported the screening for Hepatitis B to its inmates. Hepatitis B prevalence among male and female inmates were $0.20 \%$ and $0.08 \%$, respectively. All CHs lacked the provision for Hepatitis treatment, though a medical diet was offeredto HBV positive inmates in all $10 \mathrm{CHs}$.

\section{Co-morbidities among prison inmates and its management in $\mathrm{CHs}$}

The prevalence of HIV-TB among inmates was $0.08 \%$, and HIV-Hep B was $0.01 \%$, respectively. All key informants reported that the $\mathrm{CHs}$ provided preventive measures such as masks, medical diet, and isolation for HIV-TB infected inmates. All CHs provide regular medication of DOTS and ART for TB-HIV inmates. Since these $\mathrm{CH}$ s do not have the provision for treatment of Hep B, only ART was given to the inmates having HIV-Hep B co-morbidity.

\section{Needle Exchange Program}

The needle exchange programme was reportedly inactive in all $\mathrm{CHs}$, although injecting drug use among inmates were reported.

\section{Discussion:}

This study has revealed the availability of substances inside prisons and its use among inmates. A study conducted in India reported that $80 \%$ of inmates have had used one or more substances a month before their last imprisonment. They have used alcohol, cannabis, opium, opioids \& heroine, and $97 \%$ of inmates had admitted the availability of drugs inside the prison. ${ }^{8}$ 
Among the inmates who availed OST at CHs, the OST completion rate was $96.53 \%$, while the re-addiction rate after being released from prison was $98.07 \%$. These high levels of re-addiction describe the dejected prison system in educating and providing awareness to the inmates while incarcerated. Also, there was a flawed system to ensure regular clinical follow-ups and adherence to treatment for inmates after their release. After release, the inmates go back to the community and have the potential to infect community members. So, it is crucial to provide interventions in correctional home settings and community settings to break the chain of re-addiction. A similar study stated that opioid overdose is a preventable condition, and therefore educating prison inmates. At the same time, incarceration will help prevent opioid-related overdose in prison and after release. Prison authority should also ensure that prison inmates get treatment in the community when being released. ${ }^{[8]}$

Medical personnel who participated in the study stated, "Correctional homes have become a rehabilitation centre". A senior police officer has made the statement was "People, who think the home environment is inadequate to reform a family member who is under addiction, often request us to take over and rehabilitate him". These statements indicate that prison inmates get proper rehabilitation, including a healthy diet while incarcerated, making their condition better. The data matches well with the available published literature, which argued that prison improves the drug user's motivation to quit substances. It also showed the same result of restarting substance use soon after the release from prison. ${ }^{[8]}$

Homosexual practices $(0.39 \%)$ were reported among prisoners, and condom distribution has been discontinued, claiming it was against prison policy. It revealed the unprotected sexual practices and the need to reinstate the condom distribution program promoted by National AIDS Control Programme (NACP). ${ }^{[14]}$ The homosexual practices might be underestimated, as reporting such activities could result in isolation and stigmatization of such victims. A similar study revealed the discontinuation of condom among prison inmates due to misguided and exaggerated concerns about inmates' safety and security operations in prisons. ${ }^{[4]} \mathrm{A}$ study in Australia in 2012 has reported $7.1 \%$ of prison inmates involved sex without a condom with other prisoners. ${ }^{[15]}$

Though STIs was reported in inmates, only 4 out of $10 \mathrm{CH}$ s has screened its inmates for STIs. The actual prevalence could be higher if all $\mathrm{CHs}$ conduct routine STI screening in their inmates. Although NACP mandated STI screening for all key populations, the overburdening condition of medical officers and lack of skilful personnel made it impossible to achieve the target.

A higher proportion of inmates in $\mathrm{CCH}$ and $\mathrm{DCH}$ reportedly having contact dermatitis, scabies and UTIs. It indicates the pathetic state of hygiene maintenance, inadequate clean water supply and low levels of awareness among inmates. A Lancet study has shown that poor infrastructure and overcrowding were major contributing factors to disease transmission in prison settings. ${ }^{[16,17]}$

The high prevalence of HIV among inmates found in this study was comparable to the prevalence reported in other studies ${ }^{[3,4,7,17]}$. Participants reported that ART facilities for inmates were often 
interrupted, non-existing systems for partner notification in $\mathrm{CHs}$, and the continuation and linkage of ART with the health system after release of inmates, which matches the findings other studies. ${ }^{[4,19]}$

Although Hepatitis B infections were reported among male $(0.20 \%)$ and female $(0.08 \%)$ inmates, its treatment was not provided in the prisons, which narrates the inadequacy of healthcare delivery system in prison settings, this is tantamount to harbouring the infection for spreading to other inmates, these being sexually transmitted diseases. The National Viral Hepatitis Control Program in India mandate the screening, testing, and treatment of all key population groups, including prison inmates to control HBV. ${ }^{[18]}$ Apart from medical diet, no medical treatment for Hepatitis B positive or co-morbid inmates was provided in CHs. To treat HIV, the prisons follow NACP guidelines ${ }^{[14]}$ and follow the National Tuberculosis Elimination Programme ${ }^{[20]}$ guidelines for TB treatment of prison inmates.

The needle exchange program recommended by NACP ${ }^{[14]}$ was not implemented in prisons though injecting drug use was reported inside prisons. This may lead to increased risk of transmission of bloodborne infections such as HIV, Hepatitis B and Hepatitis C, which will again contribute to the higher prevalence of such severe infections within the inmates and the general community.

\section{Conclusion And Recommendation:}

The current practices and infrastructure in Indian prisons can be detrimental to non-risky inmates, as they can become high-risk individuals from their stay at prisons. The prison authorities have to ensure the safety of uninfected inmates and protect them from acquiring new infections and risk habits during their stay in prisons.

Correctional homes can serve as an ideal place to screen high-risk individuals for infectious and noninfectious diseases, addictions, and mental health disorders. Incarceration grants sufficient time for health systems to start or continue treating infectious diseases such as HIV, HBV, HCV and TB. The prisons could also ensure treatment adherence, follow-ups, and course completion of prisoners. In addition, the prison setting could be used to provide health education to affected inmates and their family members on their release from prison.

Prison authority has a separate body for health interventions, which can be linked to the nearest government health facility from where the inmate belongs. A linear approach will help break the chain of substance abuse and relapse. Social welfare and self-help groups can be involved in this process to make the interventions successful.

For the unhygienic condition due to overcrowding, proper budget allocation is required for providing necessary basic facilities.

A collaborative and multi-sectoral approach is the need of the hour to tackle the health and safety of vulnerable group like prison inmates 


\section{Abbreviations}

$\mathrm{CH}$ : Correctional Home

DCH: District Correctional Home

CCH: Central Correctional Home

\section{Declarations}

\section{Ethics approval and consent to participate:}

The authors confirm that the proposal was approved by the Institutional Ethics Committee of the Manipal Academy of Higher Education (MAHE) [IEC-880/2019, Date of Approval-13/11/2019] and Clinical Trial Registry of India (CTRI/2020/01/022802, Date of approved registration: 16/01/2020) was kept posted of the study, its progress and completion. Permission was obtained from the Director General (DG) \& Inspector General (IG) of Correctional Services, West Bengal, India.

All the authors confirm that informed consent was obtained from all subjects or, if subjects are under 16, from a parent and/or legal guardian.

Authors also state to confirm that all methods were carried out in accordance with relevant guidelines and regulations.

Consent for publication: Not Applicable

Availability of data and materials: The datasets generated and/or analysed during the current study are not publicly available due to data protection and confidentiality issues but are available from the corresponding author on reasonable request.

Competing interests: The authors declare that they have no competing interests

Funding: No funding was obtained for this study

Authors' contributions: All authors contributed to concept development, study design and definition of intellectual content. AA has solely contributed in literature research and data collection. All three authors (AA, SSH, PN) have contributed to data analysis and statistical inferences. AA and PN have contributed to manuscript preparation and editing. All authors read and approved the final manuscript.

\section{Acknowledgements}

We thank the prison authority for their cooperation in providing permission to conduct the study. We extend our heartfelt thanks to Sudha Jha from SAATHII NGO for her constant support throughout the study. 


\section{Authors' information (optional):}

1. Adhikary Anoshmita, Master of Public Health

2. Hossain Shaikh Shah, MD, MPH

3. Narayanan Prakash, MSc, PhD

Department and institution: Department of Health Policy, Prasanna School of Public Health, Manipal Academy of Higher Education, Manipal, Karnataka, 576104

\section{Corresponding Author:}

Name :Dr. Prakash Narayanan

Address: Associate Professor, Department of Health Policy, Prasanna School of Public Health, Manipal Academy of Higher Education, Manipal, Karnataka, 576104

Phone numbers : 9686570750

Facsimile numbers :+91 820

E-mail address :prakash.narayanan@manipal.edu

\section{References}

1. United Nations Program on HIV/AIDS (UNAIDS). UNAIDS Technical Support Mechanism 2019-2020. http://www.unaids.org. Accessed 15 June 2021.

2. Suresh BM, Pratima M, Rajani P, Naveen KC, Madhusudhan S. Minds Imprisoned: Mental Health Care in Prisons. National Institute of Mental Health Neuro Sciences. Bangalore: Common Mental Disorders in Prisons. 2011.

3. Joint United Nations Program on HIV/AIDS (Geneva). Prisons and AIDS: UNAIDS technical update. 1st Ed:1997. http://www.unaids.org. Accessed 15 June 2021.

4. Rubenstein L S, Amon JJ, McLemore M, Eba P, Dolan K, Lines R, et al. HIV and related infections in prisoners 4: HIV, prisoners, and human rights. The Lancet. 2016.

5. Fazel S, Bains P, Doll H. Substance abuse and dependence in prisoners: a systematic review. Addiction. 2006; 101(2):181-191.

6. Mason D, Birmingham L, Grubin D. Substance use in remand prisoners: a consecutive case study. BMJ. 1997; 315(7099):18-21.

7. Jürgens R, Ball A, Verster A. Interventions to reduce HIV transmission related to injecting drug use in prison. The Lancet infectious diseases. 2009; 9(1):57-66. 
8. Rao R, Mandal P, Gupta R, Ramshankar P, Mishra A, Ambekar A, et al. Factors affecting drug use during incarceration: A cross-sectional study of opioid-dependent persons. Indian Journal of substance abuse treatment. 2016; 61:13-17.

9. Prevention of Spread of HIV Amongst Vulnerable Groups in South Asia. United Nations Office on Drugs and Crime. 2008. http://www.unaids.org. Accessed 15 June 2021.

10. Ganguly S, Goswami D, Chakraborty D, Samanta S, Jana J. Prevalence of HIV infection among the prison inmates in West Bengal. Global Journal for Research Analysis. 2018; 8:2277-8160.

11. Ramamoorthy $M$, Venketeswaran $A$, Seenivasan $P$, Revathy $M$, Manimaran $M$, Chitra $S$, et al. Risk factors and prevalence, hepatitis $B$ virus and hepatitis $C$ virus among prison inmates, Chennai, India. International Journal of Infectious Diseases. 2016; 53:90.

12. Rana S, Girdhar N.K, Gill M.K, Kumar A. Prevalence of hepatitis-B surface antigen among population of inmates in Tihar Jail, New Delhi. International Journal of Research in MedicalSciences.2015; 3(1):100.

13. Alavi SS, Ferdosi M, Jannatifard F, Eslami M, Alaghemandan H, Setare M. Behavioral addiction versus substance addiction: Correspondence of psychiatric and psychological views. International journal of preventive medicine. 2012 Apr; 3(4):290.

14. National AIDS control Organization (India). Ministry of Health and Family Welfare (India). HIV and TB intervention in prisons and other closed settings: Operational Guidelines. 1st Ed. New Delhi:2018. http://www.naco.gov.in. Accessed 15 June 2021.

15. Richters J, Butler T, Schneider K, Yap L, Kirkwood K, Grant L, et al. Consensual sex between men and sexual violence in Australian prisons. Archives of sexual behavior. 2012; 41(2):517-524.

16. Dolan K, Larney S. HIV in Indian prisons: Risk behaviour, prevalence, prevention \& treatment. The Indian journal of medical research. 2010; 132(6):696.

17. Kamarulzaman A, Reid S.E, Schwitters A, Wiessing L, El-Bassel N, Dolan K, et al. Prevention of transmission of HIV, hepatitis B virus, hepatitis $C$ virus, and tuberculosis in prisoners. The Lancet. 2016; 388(10049):1115-1126.

18. National Health Portal (India). Ministry of Health and Family Welfare (India). National Viral Hepatitis Control Program (NVHCP): Operational Guidelines. 1st Ed. New Delhi:2018. http://www.nhp.in. Accessed 15 June 2021.

19. World Health Organization. 2020. People in Prisons and Other Closed Settings | Global HIV, Hepatitis B and STI Programs. http://www.who.int. Accessed 15 June 2021.

20. Central TB Division (India). Director General of Health Services. Ministry of Health and Family Welfare (India). National Strategic Plan for Tuberculosis Elimination 2017-2025. 1st Ed. New Delhi: Mar 2017.

\section{Tables}

Tables 1 and 2 are not available with this version 
Figures

\section{Image not available with this version}

Figure 1

Image not available with this version.

\section{Image not available with this version}

Figure 2

Image not available with this version.

\section{Image not available with this version}

Figure 3 
Image not available with this version.

\section{Image not available with this version}

Figure 4

Image not available with this version. 